\title{
Extratos vegetais no controle de brevicoryne brassicae nas brassicáceas
}

\author{
Extractos vegetales en el control de brevicoryne brassicae en brassicaceans \\ Vegetable extracts in the control of brevicoryne brassicae in brassicaceans
}

Recebido: 08/03/2021 | Revisado: 16/03/2021 | Aceito: 19/03/2021 | Publicado: 27/03/2021

\author{
Marcos Vinicius Colcheski Micheten \\ ORCID https://orcid.org/0000-0002-3493-346 \\ Universidade Cesumar, Brasil \\ E-mail: marcosviniciusmich@outlook.com \\ Isabela Leticia Pessenti \\ ORCID: https://orcid.org/0000-0002-5176-3134 \\ Universidade Cesumar, Brasil \\ E-mail: isabelaleticiapessenti@gmail.com
}

\begin{abstract}
Resumo
Neste projeto foi efetuado os testes dos compostos aquosos com extrato de fumo com álcool (Nicotiana tabacum), extrato de mamona (Ricinus communis), extrato das folhas da árvore kassod (Senna siamea), para o controle do pulgão no cultivo orgânico do brócolis (Brassica oleracea var. italica) e da couve flor (Brassica oleracea var. botrytis). Onde foi realizado no interior de Reserva/PR. Foi efetivado o teste de três canteiros com 12 plantas de brócolis com o extrato de fumo com álcool, três canteiros com o extrato de mamona, e três canteiro com o extrato de mamona, três canteiro com o extrato da folha da (Senna siamea) e três canteiro de testemunha sem os extratos, as medidas entre plantas foram de $60 \mathrm{~cm}$, os canteiros tiveram $1.20 \mathrm{~m}$ de largura por $2 \mathrm{~m}$ de comprimento com espaçamento de $50 \mathrm{~cm}$ um canteiro do outro. Onde foram acondicionados em ordem aleatória o local dos canteiros. No inverno foi implantado os brócolis ramoso cultivar Santana e no verão a couve flor cultivar Teresópolis gigante, as duas culturas com o mesmo sistema. Com o término do experimento, obteve-se as variáveis com resultados significativos, para o brócolis tivemos a massa total e controle de insetos tendo o extrato de folha da Senna siamea e extrato de mamona com média superiores, respectivamente, no ponto massa seca e fresca por plantas, o extrato de Senna siamea com eficácia superior com os demais extratos no cultivo do brócolis, na cultura do couve flor o extrato de mamona com eficácia superior no controle de insetos, em relação massa seca da inflorescência e matéria seca da inflorescência tivemos o extrato de fumo com eficácia final, ao final do experimentos em relação a controle de insetos da cultura de brócolis e de couve-flor obtevese o extrato de mamona com eficácia no controle de insetos. Para uma maior eficiência desses extratos vegetais, recomendam-se estudos mais aprimorados que envolvam diferentes concentrações dos extratos, afim de determinar uma proporção mais adequada, que permita uma maior eficiência e controle desse inseto, o que irá acarretar na redução do uso de inseticidas sintéticos para os produtores, resultados assim na diminuição dos impactos ambientais e custos de produção.
\end{abstract}

Palavras-chave: Controle alternativo; Brassicaceae; Ecologicamente sustentável.

\begin{abstract}
In this project, tests were carried out on aqueous compounds with alcohol smoke extract (Nicotiana tabacum), castor bean extract (Ricinus communis), kassod tree leaf extract (Senna siamea), for the control of aphids in the organic cultivation of broccoli (Brassica oleracea var. Italica) and cauliflower (Brassica oleracea var. Botrytis). Where it was held inside Reserva / PR. The test of three beds with 12 broccoli plants with the smoke extract with alcohol, three beds with the castor extract was carried out, and three beds with the castor extract, three beds with the leaf extract of (Senna siamea) and three control beds without extracts, the measurements between plants were $60 \mathrm{~cm}$, the beds were $1.20 \mathrm{~m}$ wide by $2 \mathrm{~m}$ long with $50 \mathrm{~cm}$ spacing between each other. Where the beds were placed in a random order. In winter, branch broccoli cultivar Santana was implanted and in summer cauliflower cultivated giant Teresópolis, both cultures with the same system. With the end of the experiment, variables with significant results were obtained, for broccoli we had total mass and insect control with Senna siamea leaf extract and castor extract with higher averages, respectively, in the dry and fresh mass point by plants, the Senna siamea extract with superior efficacy with the other extracts in the cultivation of broccoli, in the culture of cauliflower the castor extract with superior efficacy in the control of insects, in relation to the dry mass of the inflorescence and the dry matter of the inflorescence tobacco extract with final efficacy, at the end of the experiments in relation to insect control of broccoli and cauliflower culture, castor bean extract was obtained with effectiveness in insect control. For greater efficiency of these plant extracts, more improved studies involving different concentrations of the extracts are recommended, in order to determine a more adequate proportion, which allows greater efficiency and control of this insect, which will result in the reduction of the use of synthetic insecticides for producers, results in reducing environmental impacts and production costs.
\end{abstract}

Keywords: Alternative control; Brassicaceae; Ecologically sustainable. 


\begin{abstract}
Resumen
En este proyecto se realizaron ensayos sobre compuestos acuosos con extracto de humo de alcohol (Nicotiana tabacum), extracto de ricino (Ricinus communis), extracto de hoja de árbol kassod (Senna siamea), para el control de pulgones en el cultivo orgánico de brócoli (Brassica oleracea var. Itálica) y coliflor (Brassica oleracea var. Botrytis). Dónde se llevó a cabo dentro de Reserva / PR. La prueba de tres lechos con 12 plantas de brócoli se realizó con el extracto de humo de tabaco con alcohol, tres lechos con el extracto de ricino y tres lechos con el extracto de ricino, tres lechos con el extracto de la hoja de (Senna siamea) y tres lechos testigos sin extractos, las medidas entre plantas fueron de $60 \mathrm{~cm}$, los lechos fueron de 1,20 m de ancho por $2 \mathrm{~m}$ de largo con $50 \mathrm{~cm}$ de distancia de un lecho a otro. Dónde se colocaron las camas en un orden aleatorio. En invierno se implantó la rama de brócoli del cultivar Santana, y en verano se cultivó coliflor gigante Teresópolis, ambos cultivos con el mismo sistema. Con el final del experimento se obtuvieron variables con resultados significativos, para el brócoli se tuvo la masa total y el control de insectos con extracto de hoja de Senna siamea y extracto de ricino con promedios más altos, respectivamente, en el punto de masa seca y fresca por plantas, la Senna siamea. extracto con eficacia superior con los demás extractos en el cultivo de brócoli, en el cultivo de coliflor el extracto de ricino con eficacia superior en el control de insectos, en relación a la inflorescencia de masa seca y la inflorescencia extracto de materia seca de tabaco con eficacia final, al final de los experimentos en relación al control de insectos del cultivo de brócoli y coliflor, se obtuvo extracto de ricino con efectividad en el control de insectos. Para una mayor eficiencia de estos extractos vegetales, se recomiendan estudios más mejorados que involucren diferentes concentraciones de los extractos, con el fin de determinar una proporción más adecuada, que permita una mayor eficiencia y control de este insecto, lo que redundará en una reducción en el uso de sintéticos. insecticidas. para los productores, resulta en la reducción de impactos ambientales y costos de producción.
\end{abstract}

Palabras clave: Control alternativo; Brassicaceae; Ecológicamente sostenible.

\title{
1. Introdução
}

A espécie Brassica oleracea L., família Brassicaceae, engloba um grupo de variedades botânicas A de grande interesse na alimentação humana. Nesse grupo encontra-se o brócolis (Brassica oleracea L. var. italica), planta herbácea, folhosa e morfologicamente semelhante à couve-flor, especialmente na fase vegetativa (Filgueira, 2008). O ponto de colheita ocorre quando a cabeça central ou as ramificações laterais apresentam se com botões florais bem desenvolvidos, com coloração verdeescura, porém antes da abertura das flores (Filgueira, 2008; Vieira; Peres, 2017).

De modo geral, pode-se analisar a suma importância das olerícolas no Brasil, vemos a importância nutricional e também se geração de renda para pequenos produtores rurais. A olericultura engloba uma vasta quantidade de espécies, as quais são caracterizadas como culturas folhosas, possui raízes e bulvo, podendo conter tubérculos e frutos de diversos tipos, possui mais de 100 espécies nesta classe (Machado, 2007). Neste grupo encontra-se o brócolis (Brassica oleracea var. itálica) e também o couve flor (Brassica oleracea var. botrytis). Observa-se a importância da agricultura familiar para o sustento de pequenos produtores, pois podemos notar que é muito comum o consórcio de outras hortaliças, podendo ter mais de uma renda, observase que as olerícolas possui um ciclo de 90 a 120 dias, dependendo da variedade observa-se que é um curto prazo onde torna-se viável o cultivo juntamente com seu baixo custo de produção, tornando-se assim um atrativo para a produção.

Segundo o Departamento de Economia Rural (Deral) da Secretaria de Estado da Agricultura e do Abastecimento em dez anos tivemos um crescimento na produção de olerícolas no Paraná com crescimento de $82 \%$ trazendo uma produção que era de 1,71 milhão em 2007 para 3,12 milhões de toneladas em 2017 (Paraná, [2018]). Podemos ver que ela e de suma importância para a economia num modo geral.

A cultura do brócolis teve um impulso no decorrer dos anos onde se tornou um produto importante para o cultivo, podemos ver que está ganhando cada vez mais espaço no setor culinário, esse alimento possui propriedades nutricionais onde estão diretamente ligado a uma alimentação saudável ("Plantar-Brócolis" 2015), onde têm-se notado um ganho de espaço entre a população. Os brócolis podem ser consumidos de inúmeras formas, natural, em forma de salada, cozido e está presente em diversos pratos na culinária. Trazendo inúmeros benefícios além da importância econômica e alimentícia esta olerícola acarreta um impacto social com a geração de empregos traçando uma linha do tempo analisamos uma grande demanda de mão de obra desde o plantio até a industrialização.

Em relação ao cultivo de brócolis ele se adapta melhor com temperaturas amenas, onde -e favorável para a formação 
da inflorescência, o clima é um fator importante para a produção que está diretamente ligado a formação e desenvolvimento da planta num todo. Vendo num modo geral entre as cultivares disponíveis de brócolis, a temperatura ideal é de $20^{\circ} \mathrm{C}$ e $24^{\circ} \mathrm{C}$ e $15^{\circ} \mathrm{C}$ a $18^{\circ}$, no estádio que antecede a emergência da inflorescência e após a emergência da inflorescência, respectivamente ("Brócolis", 2015).

A couve - flor é uma cultura muito produzida que está ganhando cada vez mais espaço, possui um alto valor nutritivo, rica em cálcio, fosforo, ácido fólico e também vitamina C. Muito consumida de diversas formas como natural, gratinada, empanada, saladas e também e ingrediente de diversas tortas entre outros pratos culinários ou também consumida apenas cozida (Resende*, 2013), com isso está ganhado espaço entre o consumo da população.

Com o surgimento de novos híbridos, juntamente com melhoramento genético consegue-se produzir o couve flor o ano todo. Porém, a escolha da cultivar ideal para o plantio é um fator muito importante, pois a temperatura influencia diretamente na produção, podendo causar inúmeros problemas na planta e em sua formação, assim como na sua inflorescência. A temperatura adequada para o couve - flor é de $14{ }^{\circ} \mathrm{C}$ a $20^{\circ} \mathrm{C}$. Acima de $25^{\circ} \mathrm{C}$ ocorre má formação da planta e das inflorescência, podendo causar danos e percas na produção(“Cultura da Couve-Flor”, 2007).

Um dos maiores problemas no cultivo de hortaliças é as pragas, que são amplamente diversificadas, como insetos, lagartas, pulgão entre outras, onde causam danos e prejuízo. O surgimento destas pragas são decorrentes de algum desequilíbrio no manejo inadequado como adubação, irrigação, monocultura(“Silveira”, 2017).

Em olerícolas, a principal praga é o pulgão (Brevicoryne brassicae L.,) a praga chave do brócolis é nativo do continente europeu, porém comumente encontrado nas Américas (Ahmad; Akhtar, 2013). O tempo de desenvolvimento curto pode resultar em 15 a 20 gerações por ano, dependendo das condições climáticas. Assim, atingem facilmente altas densidades, o que compromete a qualidade e produtividade das culturas que atacam. Os pulgões se alojam na parte abaxial das lâminas foliares mais jovens. Sua sução contínua de seiva provoca clorose e o enrugamento foliar, além de introduzir toxinas no sistema vascular da planta. Produzem excremento açucarado, que provoca o crescimento de fungos conhecidos como fumagina na superfície das folhas, reduzindo a área fotossintética (Leite et al., 2011).

Umas das maiores preocupação da atualidade é o uso excessivo de agrotóxicos para combater as pragas, com isso surge a possibilidade de utilizar um meio alternativo que possa combater as pragas, com uso reduzido de produtos químicos, ao que se refere o uso de extratos vegetais. Extratos são soluções aquosas extraídos de matéria prima vegetal, (podendo ser moído, esmagado, etc), onde se extrai o liquido da planta escolhida (Morais Júnior et al., 2012).

Com isso, há inúmeras plantas que possuem poder repelente ou até mesmo ocasiona a mortalidade dos insetos, além reduzir o uso de produtos químicos, tem redução de custo. Além de inúmeras vantagens, nota-se a disseminação de resistência do inseto, pois ao analisar as plantas nota-se mais de um princípio ativo, com isso produz repelência contra insetos, inibição da alimentação, mutação no crescimento do inseto, alterações hormonais, mudança no comportamento sexual(Dietrich et al., 2011). Ou seja, modificando a cadeia produtiva causando diminuição na população de pragas.

Dentro desse contexto, o presente trabalho teve como objetivo analisar o efeito da aplicação dos extratos vegetais de fumo com álcool (Nicotiana tabacum), extrato de mamona (Ricinus communis), extrato das folhas de Cássia-de-sião (Senna siamea), na cultura de brócolis no inverno e couve flor no verão na Região de Reserva - Paraná.

\section{Metodologia}

O experimento foi realizado em uma propriedade rural localizada no município de Reserva-Paraná. De acordo com Koppen, a classificação climática do local é Cfb (Alvares et al., 2013). Onde testou-se os extratos de fumo com álcool (Nicotiana tabacum), extrato de mamona (Ricinus communis), extrato das folhas de Cássia-de-sião (Senna siamea), coletadas em plantas adultas presente na área. 
Realizou-se as coletas das folhas no final do outono/início do inverno, de vários pontos da copa, todos com grande incidência luminosa. Para o preparo dos extratos aquosos, as folhas coletadas foram lavadas com água, sendo descartadas as que apresentavam qualquer sintoma de ataque de pragas ou patógenos, para garantir o uso de folhas saudáveis. Após a lavagem, colocou-se as folhas para secar sobre papel toalha e em seguida, trituradas em liquidificador com 1 litro de água durante dois períodos de 15 segundos, com intervalo de três minutos entre eles. Em seguida as suspensões dos extratos permaneceram em repouso em recipiente fechado com filme de PVC esticável por um período de 24 horas, sob temperatura ambiente e sem luminosidade. Após este período, foi filtradas as misturas, e acondicionados em galões limpos e secos para serem transportados até o campo. No campo, as suspensões preparadas foram diluídas para obtenção do volume final de 4 litros. O preparo dos extratos será conforme Santos et al. (2014), com modificações.

Foram preparados doze canteiros distribuídos aleatoriamente, onde tivemos o composto de fumo com álcool (Nicotiana tabacum), extrato de mamona (Ricinus communis), extrato das folhas de Cássia-de-sião (Senna siamea) e um a testemunha (sem aplicação de extratos) respectivamente tr1, tr2, tr3 e a testemunha. Cada canteiro tendo sua medida de $(1 \mathrm{~m})$ de largura, $(3 \mathrm{~m})$ de comprimento onde foram acondicionadas 12 plantas com $0,50 \mathrm{~m}$ entre linhas e $0,50 \mathrm{~m}$ entre plantas totalizando em 144 plantas transplantada na área experimental.

Foram acondicionadas armadilhas para coleta dos insetos e afídeos, para produzi-las utilizou-se produtos reciclável como garrafas pet descartáveis, onde foi pintado na cor amarela, pelo interior da garrafa, onde tem mais qualidade e durabilidade a tinta, no exterior da garrafa foi utilizado uma mistura feita com breu e óleo de soja, formando uma cola, onde o óleo de soja e responsável pela impermeabilização da cola a campo e para dissolver o breu. Após a fabricação desta cola, foi utilizado um pincel para passa no exterior da garrafa. Foram acondicionas uma garrafa por canteiro com uma estaca de madeira e uma linha amarrando-a em uma altura em torno de $0,30 \mathrm{~m}$ do solo, após este processo com um intervalo d três dia e feito a contagem de insetos e a pulverização das plantas e acondicionando novamente para coleta de dados antes e após a aplicação.

Aplicou-se os extratos utilizando-se um pulverizador costal manual, com capacidade para 5 litros, munido de bico tipo cone, com jato dirigido, de modo a molhar completamente toda planta, principalmente inflorescências e a parte abaxial das folhas. Se realizou as aplicações a partir das 15 horas, visando minimizar a ação dos raios ultravioleta sobre os produtos utilizados.

\subsection{Cultura Do Brócolis}

Implantou-se os brócolis ramoso da variedade Santana. É uma planta vigorosa, desenvolve ramificações, podendo-se efetuar mais de uma colheita em uma mesma planta, possui ciclo de 80 a 110 dias. Adapta-se em temperaturas amenas e frias ("Brócolis Ramoso Santana", 2011). O transplante das mudas na área experimental ocorreu no dia 30/05/2020. Sendo distribuídas nos doze canteiros aleatoriamente. Houve um aproveitamento de $100 \%$ das mudas transplantada. Vinte dias após o transplante, realizou-se a primeira aplicação dos extratos com calda de $1 \mathrm{~L}$ de água e 100ml de extratos, após a segunda aplicação dos extratos, com intervalo de 15 dias, houve redução nas folhas danificadas por insetos, observou-se queda na população de insetos, 30 dias após a segunda aplicação se realizou o acondicionamento das armadilhas para captura dos insetos e dos afídeos.

Com 90 dias após o transplante, realizou-se a primeira colheita, onde efetuou-se as colheitas com intervalos de 15 dias, com esse período formavam-se novas inflorescências, o período de produção do experimento da cultura dos brócolis teve a durabilidade de 34 dias de formação de novas inflorescência, onde se efetuou a pesagem, contagem das inflorescências, medição do diâmetro das inflorescências.

Após o final da produção foram retiradas as plantas e efetuado a medição de uma haste principal e pesagem de uma planta para cada repetição. Foi efetivado o revolvimento do solo para preparação para próxima cultura. 


\subsection{Cultura do couve flor}

$\mathrm{Na}$ cultura do couve flor foi utilizado a variedade Teresópolis gigante, com ciclo de 100 a 115 dias, propicia para temperaturas amenas em média $18^{\circ} \mathrm{C}$ a $25^{\circ} \mathrm{C}$. É uma hortaliça do tipo inflorescência, apresentando uma inflorescência central apenas.

Após o preparo dos canteiros e a adubação se realizou o transplante das mudas. Onde ocorreu no dia 16/09/2020. Este período do plantio tivemos uma escassez hídrica, onde dificultou no desenvolvimento das mudas. Para amenizar o problema hídrico foi feito uma camada com matéria seca, usando como cobertura no solo, deixando o mesmo protegido com isso o solo manteve-se húmido por mais tempo.

A primeira aplicação dos extratos ocorreu 25 dias após o transplante, nota-se uma população de pulgões acentuada, pois o clima seco com isso favoreceu o desenvolvimento da população de afídeos. Foram feitas aplicações com intervalos de 7 dias para controle de pragas. Cada aplicação foi realizada a coleta de dados da população de pulgões, onde foram escolhidas duas plantas aleatórias de cada canteiro, realizando-se a contagem.

A formação da inflorescência começou em torno de 90 dias após o transplante. A primeira colheita ocorreu com 109 dias após o transplante, na colheita foi coletada a massa e diâmetro de cada inflorescência, foi separado uma inflorescência de cada canteiro para realizar a secagem, onde foi retirado em média 100 gramas para colocar na estufa a $105^{\circ} \mathrm{C}$. Após o final da produção foram retiradas as plantas e efetuado a medição de uma haste principal e pesagem de uma planta para cada repetição.

\section{Resultados e Discussão}

\subsection{Cultura do Brócolis}

Após a pesagem da produção a massa total de inflorescência, obteve-se média superior (3907 g) para extrato das folhas de Cássia-de-sião, conforme Fig. 1A. Em relação ao controle de eficiência de insetos foi maior para o extrato de mamona (72\%), seguido do extrato de fumo, extrato de cássia-de-sião e testemunha, com 44, 32 e $34 \%$, respectivamente (Figura 1B).

Na planta da mamona encontra-se um fenômeno quioecológico, onde metabólitos secundários são produzidos em determinadas espécies vegetal, são liberados e interferem no desenvolvimento de outras plantas , o termo alelopatia define-se como efeitos produzidos por determinadas espécies nos quais possibilita ação diretamente ou indiretamente em outras plantas ou em microrganismos, podendo ser benéficos ou prejudiciais (Borges et al., 2011). Dessa forma, é interessante detectar, isolar e caracterizar essas moléculas de defesa presentes naturalmente nas plantas e utilizá-las no controle de pragas ou doenças que afetam a produção agrícola. Apesar de diversas moléculas oriundas de plantas terem sido caracterizadas, o modo de ação de poucas é conhecido

Uma classe muito conhecida de compostos secundários presentes em plantas são os inibidores de tripsina, uma serinoprotease relacionada com a digestão primária de proteínas. Esses inibidores apresentam a propriedade de inibir enzimas relacionadas com a digestão protéica e impedem que o organismo que os ingere tenha seu desenvolvimento adequado, podendo até mesmo interromper o ciclo de vida da espécie em questão (Rossi et al., 2010). Na espécie (Ricinus communis L.) contem grande quantidade de óleos em sua estrutura cerca de (48\% a 50\%), onde esses óleos são tóxicos, pois contém uma proteína denominada tripsina.(Borges et al., 2011).

A cultura do fumo considera-se a cultura, sendo não alimentícia, mais produzida no mundo. Sua produção ocupa 3\% da área cultivada. Em sua composição encontra-se a nicotina, onde considera-se um dos primeiros fitoinseticida utilizados. Em relação a estrutura da planta do fumo pode-se variar dependendo da região cultivada (Madaloss, 2015).

Nicotina se considera uma toxina, na qual tem sua ação no sistema nervoso, liga-se a receptores da acetilcolina também nas sinapses do axônio, onde tem ação direta no organismo, ela possui efeito de 24 horas onde não deixa resíduos, possui efeito de contato e fumigação se utilizada no controle de pulgões, cigarrinha, tripes, moscas-branca, muito utilizado em uso doméstico 
como em jardins e hortas pois não possui residual(Moreira et al., 2006).

Figura 1 - Massa total (a) e Eficiência de controle de insetos (b) (\%) para a variedade de brócolis Santana na safra 2020/2021. Os tratamentos: Testemunha, extrato de fumo com álcool, extrato de mamona e extrato de cássia-de-sião. Médias seguidas de mesma letra não diferem entre si pelo teste de Scott Knott $(\mathrm{p} \leq 0,05)$.
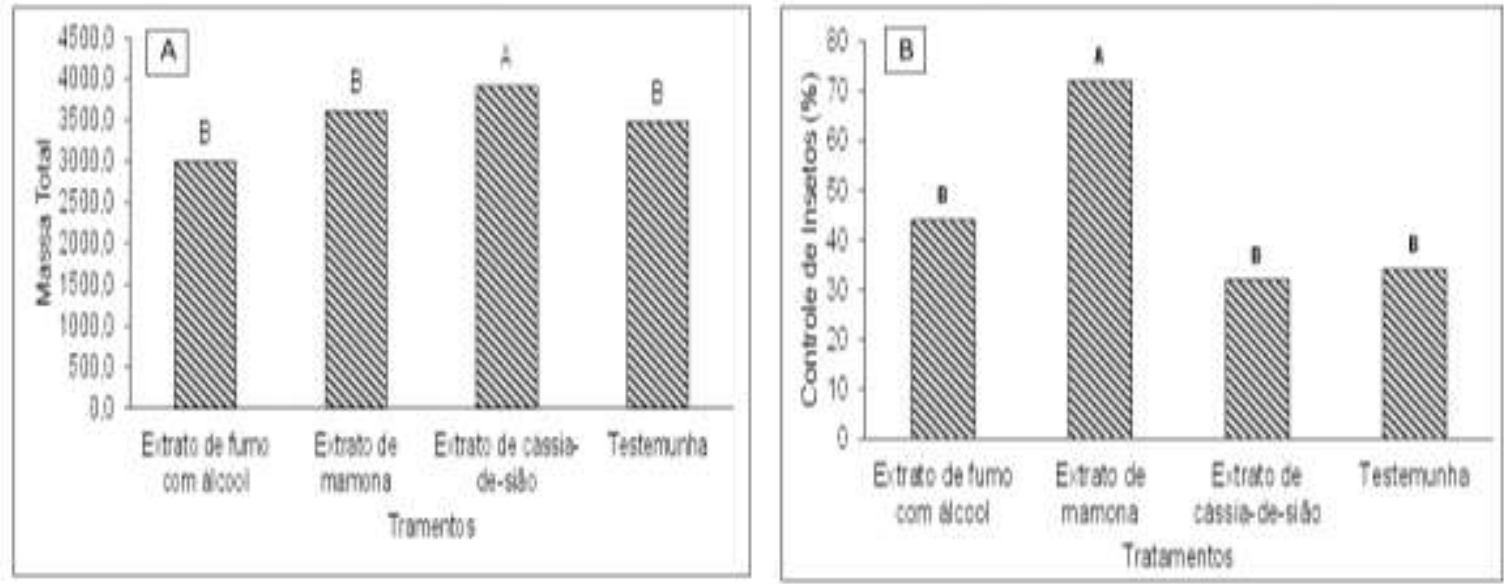

Fonte: Autores.

Realizou-se a coleta da massa fresca por planta e massa seca por planta, onde se retirou as inflorescências efetuou-se a pesagem e após isso foi feito a secagem da inflorescência. Observa-se que o extrato de cassia-de-sião, obteve uma média superior em relação aos demais (Figura 2Ae 2B), para as variáveis de massa seca e fresca. Esta cultivar dos brócolis ramoso, se adaptou ao clima do período do experimento, onde se obteve temperaturas amenas. No período do experimento foi no final do outono e o inverno, como não teve geadas ou frio excessivo, alcançou uma temperatura ideal para os brócolis, trazendo junto a isso qualidade das inflorescências.

Nesta fase da cultura dos brócolis teve uma ideal precipitação de chuva, assim como no decorrer dos demais estádios de formação, também foi feito a irrigação diária, com o volume de chuva ideal, não teve infestação desordenada do pulgão, pois em períodos chuvosos afeta na reprodução do pulgão, com esses fatores obteve um produto final de qualidade.

Figura 2 - Massa fresca por planta (a) e massa seca por planta (b) para a variedade de brócolis Santana na safra 2020/2021. Os tratamentos: Testemunha, extrato de fumo com álcool, extrato de mamona e extrato de cássia-de-sião. Médias seguidas de mesma letra não diferem entre si pelo teste de Scott Knott $(p \leq 0,05)$.
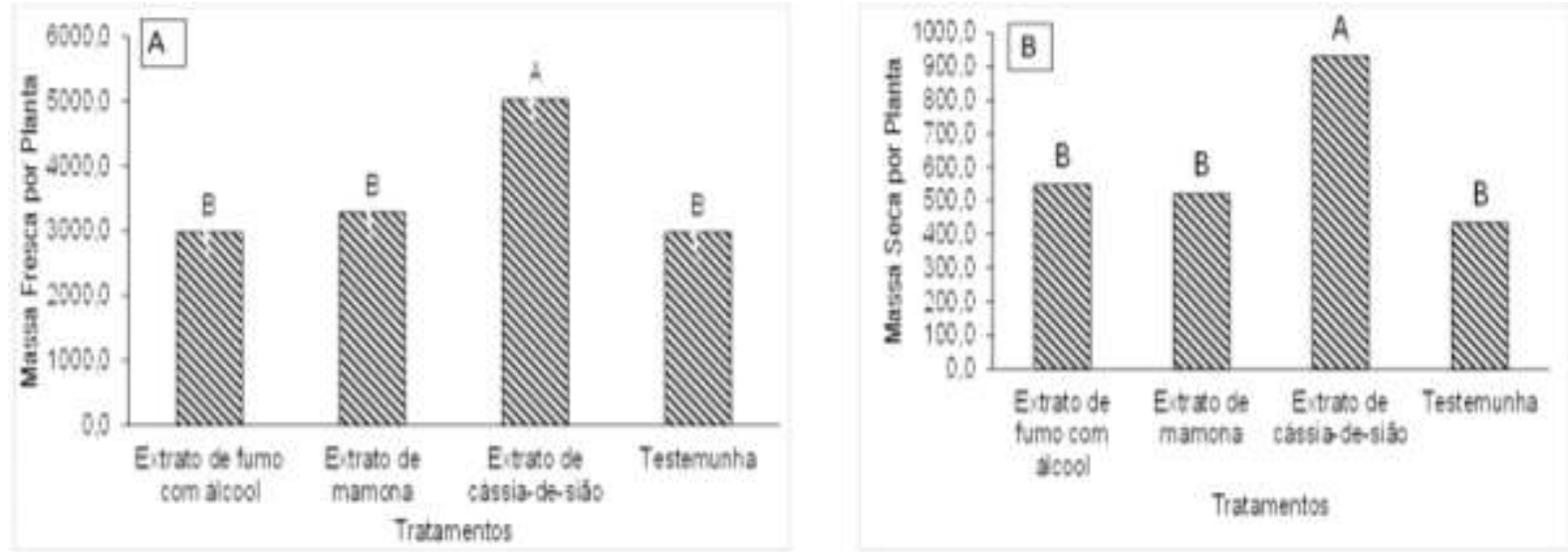

Fonte: Autores 


\subsection{Cultura do Couve-flor}

Durante implantação do couve flor ocorreu intempéries que acarretou em percas de produção e baixa qualidade do produto final. O principal fator foi a falta de chuva, onde por aproximadamente 30 dias sem chuva no período do transplante, onde ocorreu falhas no desenvolvimento das mudas, obteve-se uma alta infestação de insetos juntamente com o desenvolvimento desordenado do pulgão. Foram feitas 6 aplicações dos extratos, com período variando de 7 a 10 dias de intervalo, onde com o calor excessivo tivemos estresse na planta consequentemente um deficiente desenvolvimento, consequentemente aumento na infestação de pragas, acarretando inúmeras perdas de produção.

$\mathrm{Na}$ couve flor, como na maioria das olerícolas, o clima é um fator determinante, pois está ligado diretamente ao seu desenvolvimento, onde no processo da formação da cabeça ocorre-se entre a passagem da fase vegetativa para fase reprodutiva, ou seja, quando a diferenciação do meristema apical, esta passagem ocorre cerca de 40 dias após o plantio, este período é fundamental para a formação mínima das folhas. Em relação a subdivisão do ciclo da couve flor temos quatro estagio, onde são fundamentais o clima neste período(Barral; Souza, 2019), com o calor excessivo as plantas estão mais suscetíveis a doenças e a disseminação de pragas, e sua inflorescência apresenta coloração esverdeada.

Com todos esses problemas, teve uma alta infestação de pulgão, levando a realizar seis aplicação durante o desenvolvimento da planta, mesmo com aplicações com curto intervalo de tempo, não foi tão efetivo o controle de afídeos, chegando a uma pequena margem de controle (Figura 3). Os dois principais extratos que tiveram êxito no controle foi o t2 (extrato de mamona) t1 (extrato de fumo com álcool), respectivamente foram os com melhores resultados no controle dos afídeos.

Figura 3 - Eficiência de controle de insetos (a) (\%) para a variedade de couve flor Teresópolis gigante na safra 2020/2021. Os tratamentos: extrato de fumo com álcool (T1), extrato de mamona (T2) e extrato de cássia-de-sião (T3) e testemunha (T4). Médias seguidas de mesma letra não diferem entre si pelo teste de Scott Knott $(\mathrm{p} \leq 0,05)$.

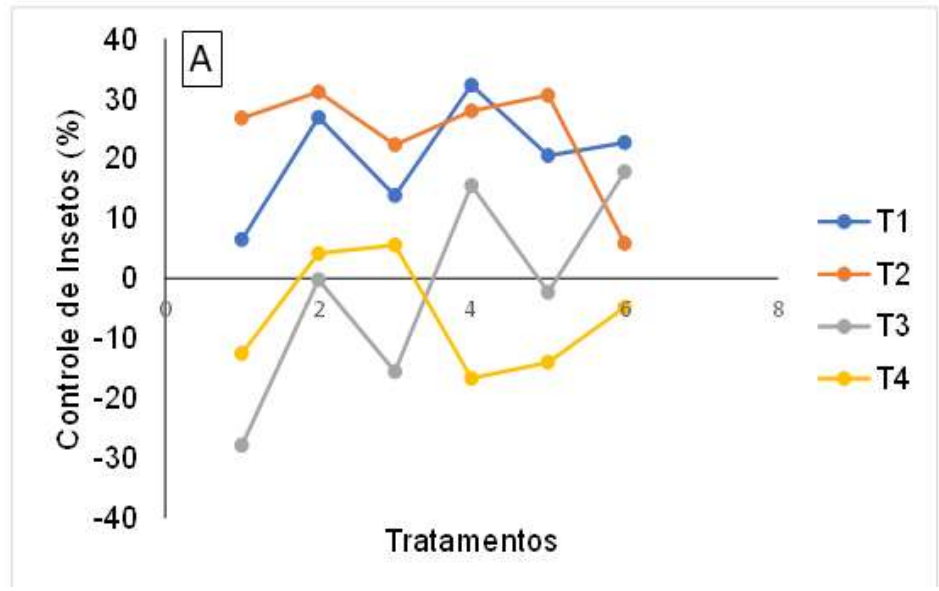

Fonte: Autores

Onde vemos que o ponto analisando massa seca e matéria seca que foram significativas vemos que o extrato de fumo com álcool teve resultado superior sobre os demais, como observa-se na Figura 4A e 4B, respectivamente. 
Figura 4 - Massa seca da inflorescência (g) (a), matéria seca da inflorescência (\%) (b) para a variedade de couve flor Teresópolis gigante na safra 2020/2021. Os tratamentos: Testemunha, extrato de fumo com álcool, extrato de mamona e extrato de cássiade-sião. Médias seguidas de mesma letra não diferem entre si pelo teste de Scott Knott ( $\mathrm{p} \leq 0,05)$.
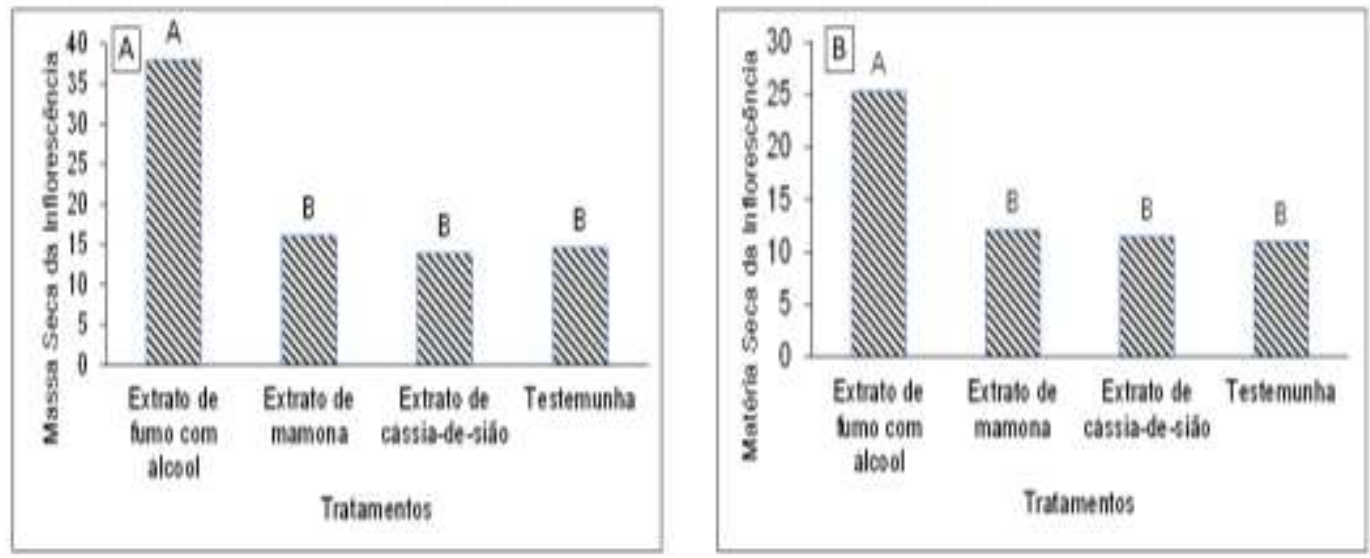

Fonte: Autores

$\mathrm{Na}$ busca de novas alternativas de controle menos agressivas, tem-se verificado que muitos dos extratos de plantas apresentam propriedades antifúngicas, sendo utilizados com sucesso no controle de fungos fitopatogênicos. Extratos naturais de plantas estão sendo cada vez mais pesquisados, e em grande parte dos testes, já com efeito comprovado, para o controle de pragas. A atividade inseticida de extratos de plantas pode ser manifestada através de diversas características tais como: mortalidade direta, repelência, esterilidade, interferência no desenvolvimento e modificação no comportamento dos artrópodes (Ferreira, 2019; Rossi et al., 2010).

Os extratos vegetais, apresentam algumas vantagens sobre os agrotóxicos, tais como: novos compostos que as pragas ainda não são capazes de inativar, menos tóxicos do que compostos químicos, biodegradação rápida e múltiplos modos de ação, tornando possível um amplo espectro de uso enquanto retêm uma ação seletiva dentro de cada classe de praga. Devido à sua baixa toxicidade para o homem e animais, e sua eficiência contra várias espécies de inseto-praga, cada vez mais mostra que o controle de inseto praga, através de produtos naturais oriundos de plantas, surge como uma alternativa para os programas de Manejo Integrado de Pragas. Por serem produtos naturais, é comum considerar que os extratos vegetais, são seguros para a utilização humana e animal, por este motivo vem se tornando cada vez mais frequente o seu uso nos campos agrícolas. Inúmeras são as pesquisas sobre o potencial fitoinseticida de algumas plantas nativas Juazeiro, Neem, Cebolinha etc. A mamona, Ricinus communis, demonstrou ser eficiente no combate a formigas cortadeiras em testes feitos por (Ferreira, 2019).

\section{Considerações Finais}

Com a realização do experimento, o uso de extratos na agricultura familiar é uma alternativa com custo baixo de aquisição e preparo e traz resultados satisfatórios, pois o pulgão foi controlado, assim como demais pragas das brassicas sem o uso de inseticidas, sendo possível obter plantas de qualidade, cultivo orgânico e sem o uso de produtos químicos.

No fator controle de inseto, observa-se que nas duas culturas o extrato de mamona e de fumo com álcool, respectivamente, trouxeram resultados positivos no controle do afídeos, no decorrer do desenvolvimento da planta.

Com o manejo de olerícolas em dois períodos diferentes, como o brócolis no outono/inverno, e o couve-flor no verão, ao analisarmos o manejo, qualidade do produto infestações de pragas, tendo em visto os diversos trabalhos na literatura, a temperatura é fundamental na produção está diretamente ligado no manejo da planta.

Para se obter uma produção lucrativa com qualidade, se deve analisar principalmente a cultivar e o clima do período 
que se irá plantar, com isso irar amenizar a infestação de pragas e chegando ao produto final de qualidade. Os extratos eficazes no cultivo dos brócolis foram o extrato de mamona e o extrato de fumo com álcool, respectivamente com resultados superiores com relação aos demais.

No cultivo dos brócolis, o extrato cássia-de-sião foi relativamente maior no ponto massa total e massa seca por inflorescência, onde teve um resultado superior em relação aos demais extratos.

$\mathrm{Na}$ cultura do couve-flor, os problemas hídricos acarretaram no desenvolvimento e na qualidade da planta e da inflorescência. Em relação a controle de insetos, o extrato de mamona e extrato de fumo com álcool apresentaram os melhores resultados, respectivamente.

Para uma maior eficiência desses extratos vegetais, recomendam-se estudos mais aprimorados que envolvam diferentes concentrações dos extratos, afim de determinar uma proporção mais adequada, que permita uma maior eficiência e controle desse inseto, o que irá acarretar na redução do uso de inseticidas sintéticos para os produtores, resultados assim na diminuição dos impactos ambientais e custos de produção.

\section{Referências}

Ahmad, M., \& Akhtar, S. (2013). Development of insecticide resistance in field populations of Brevicoryne brassicae (Hemiptera: Aphididae) in Pakistan. Journal of economic entomology, 106(2), 954-958.

Barral, D. de S., \& Souza, R. de. (2019). Avaliação das trocas gasosas na cultura da couve-flor (Brassica oleracea var. Botrytis) submetidas a diferentes tensões de água no solo e doses de Boro.

Borges, C. de S., Cuchiara, C., Silva, S. dos A., \& Bobrowski, V. (2011). Efeitos citotóxicos e alelopáticos de extratos aquosos de Ricinus communis utilizando diferentes bioindicadores. Embrapa Clima Temperado-Artigo em periódico indexado (ALICE).

Cultura Da Couve-Flor. http://www.iac.sp.gov.br/publicacoes/arquivos/iacbt200.pdf

Dietrich, F., Strohschoen, A. A. G., Schultz, G., Sebben, A. D., \& Rempel, C. (2011). Utilização de inseticidas botânicos na agricultura orgânica de Arroio do Meio/RS. Current Agricultural Science and Technology, 17(2).

Ferreira, V. B. (2019). Avaliação De Extratos De Mamona Ricinus communis E Do Coité Crescentia cujete L. No Controle De Aphis craccivora Koch (Hemiptera: Aphididae) Em Feijão Caupi. Universidade Federal Rural de Pernambuco.

Filgueira, F. A. R. (2008). Novo manual de olericultura: Agrotecnologia moderna na produção e comercialização de hortaliças ( $3^{\mathrm{a}}$ ed.), Universidade Federal de Viçosa.

Leite, G. L., Picanço, M., Zanuncio, J. C., Moreira, M. D., \& Jham, G. N. (2011). Hosting capacity of horticultural plants for insect pests in Brazil. Chilean journal of agricultural research, 71(3), 383.

Machado, L. A. (2007). Uso De Extratos Vegetais No Controle De Pragas Em Horticultura. 4.

Madaloss, S. L. (2015). Morfologia e efeito inseticida de extrato de fumo, cultivado em diferentes condições hídricas de substrato. https://rd.uffs.edu.br:8443/handle/prefix/273

Morais Júnior, O. P. de, Cardoso, A. F., Leão, É. F., \& Peixoto, N. (2012). Desempenho de cultivares de couve-flor de verão em Ipameri. Ciência Rural, 42(11), $1923-1928$.

Moreira, M. D., Picanço, M. C., Silva, E. da, Moreno, S. C., Martins, J. C., Venzon, M., de Paula, T., \& Pallini, A. (2006). Uso de inseticidas botânicos no controle de pragas. Controle alternativo de pragas e doenças. Viçosa: EPAMIG/CTZM, 89-120.

Paraná, A. E. de N. do E. do. ([s.d.]). Produção de hortaliças cresce $80 \%$ em dez anos no Paraná. Agência Estadual de Notícias. Recuperado 18 de janeiro de 2021, de http://www.aen.pr.gov.br/modules/noticias/article.php?storyid=101757

Plantar-Brocolis-ed-01-2015.pdf. ([s.d.]). Recuperado 18 de janeiro de 2021, de https://ainfo.cnptia.embrapa.br/digital/bitstream/item/142779/1/PLANTARBrocolis-ed-01-2015.pdf

Resende*, J. M. | C. F. V. (2013). Como plantar couve-flor. Revista Globo Rural. https://revistagloborural.globo.com/vida-na-fazenda/comoplantar/noticia/2013/12/como-plantar-couve-flor.html

Rossi, G. D., Santos, C. D. dos, Cardoso, M. das G., Corrêa, A. D., Abreu, C. M. P. de, \& Paiva, L. V. (2010). Inibição da tripsina de bicho-mineiro do cafeeiro por um fator não-protéico presente em extratos de folhas de mamona. Ciência e Agrotecnologia, 34(2), 361-366. https://doi.org/10.1590/S141370542010000200013

Vieira, M. R., \& Peres, L. S. (2017). Uso De Extrato Foliar De Nim, Azadirachta Indica A. JUSS, Para O Controle Do Pulgão Brevicoryne brassicae (L.) Em Cultivos De Brócolis. Cultura Agronômica: Revista de Ciências Agronômicas, 26(4), 492-501. 